\title{
BLIND PEOPLE BEHAVIORS TO THE ARCHITECTURE OF SEKOLAH LUAR BIASA (SLB) MTS YAKETUNIS
}

\author{
KURNIAWAN, Harry ${ }^{*}$; MAHARANI, Rizka Tiara ${ }^{2}$; Hs, Atika Rahmawati \\ ${ }^{1}$ Department of Architecture \& Planning (DAP), Universitas Gadjah Mada \\ Jalan Grafika 2, Yogyakarta, 55281 \\ ${ }^{2,3}$ Student, DAP, Universitas Gadjah Mada \\ *Corresponding Author: selamatpagi2001@yahoo.com
}

\begin{abstract}
People who are considered as users or even the inhabitants are the central issue in architecture; therefore it is essential to understand them before making the design. One of the users who have special character are blind people. This paper discusses the interaction between architecture and blind people by observing the blind students' mobility at Sekolah Luar Biasa (SLB)/extraordinary school MTs Yaketunis Yogyakarta. This research also conducted interviews to confirm the observation result. The purpose of the research is to identify the characteristics of blind people during their interaction with architecture and elements of architecture. The observation and interview done during the research has been recorded several interesting facts, such as how they walked through the corridor, the arrangement method of information about rooms, and the way to find each room. This information is expected to be useful information for creating better and more suitable environment for them.
\end{abstract}

Keywords: Blind; behavior; architecture.

\section{INTRODUCTION}

Character and attitude of a person is constructed both as inheritance and as the result of his/her environment-including architecture-influences. As an art, architecture is not only an effort for accomplishing functional requirements but also a physical embodiment of architecture as a container of human activities (Ching, 1996). This physical embodiment will involve a lot of architectural elements such as materials, colors, sounds, textures, light, or even space itself. Each elements affect architecture differently as described below:

\section{Material}

Material is a significant element of construction which gives the skin or message of architecture and influences the shape and quality of space. Related to the interaction between architecture and its users, material -with its textures and composition, or color and smell-will stimulus users' behavior. The habit of a person walking on wood floors, or reinforced concrete, or steel sheets will be very different, depends on attributes such as elasticity, sound, and the heat absorption rate.

\section{Sound}

The sound can be as strong as the light in terms of identifying place. The place can be distinguished from noises or effect of the sounds they make. A place may be distinguished by the sound of wind in the leaves of trees or a fountain or water flow. A particular place in the city could be associated with the music of a musician played there. A spot-like exam room or the library or the dining room of a monastery - may be distinguished by the silence; or a restaurant with its background music (Unwin, 2003).

\section{Smell}

A place can be identified by the smell and the smell can make the place. Not only could be fun, but smell could also be disgusting. Strong smell can beat all spatial aspects and turn a place into a place where nobody wants to stay. Unwin (2003) gives a few examples of places that can be identified from their smell. He said: "the character of an old library, in part, is because of the smell of polished wood and leather binding of the book; and an artist studio with the smell of oil paint. An eating place in department stores produces the smell of roast, fine cheeses, and freshly baked bread. Chinese temple is surrounded by the smell of burning incense. Teen bedroom may be distinguished by the smell of the old stiff shirts or deodorant. Different parts of a garden may be distinguished by the perfume of roses, honey, jasmine, and lavender". Based on some examples above, we agree and optimistic that the 'smell' is an element that can be modified to create a universal architecture design. 


\section{Color}

Color is not only related to the decoration or the creation of a place with a particular atmosphere. Color can also be used to identify a place, divides the space into regions and zones, and changes the focal point in the room. The ceiling in white room with black floor will appear higher than if the colors are applied upside down. Similarly, with a room that is painted green, blue room with electric light or room lit by sunlight through stained glass windows will also have different characters. Colors influences the way we perceive the boundaries of space. Rooms with low contrast colors will give the impression of larger and bigger because the distance between observer and structural surfaces and dimensions cannot be clearly identified and vice versa. Various colors and different light qualities can also show different moods (Unwin, 2003; Exner and Pressel, 2009).

Color is also used as the symbol. When directing someone to your residence, you might describe it as a house with red (blue, green, or any colors). A colored line can also show certain pathways, a place where you have to wait, or to help people find the way (Unwin, 2003).

\section{Scale}

Scale is a relative measurement. In architecture, scale has a different meaning although it is still related to the relative size refers to the size of the human body or the so-called human scale. Radically, scale is able to influence one's experience about a particular space. For example, a football field and a small patch of grass in the back garden will have different experiences of space because their scale is different, even when both are covered by grass (Unwin, 2003). The influence of environment becomes important topic learned in environmental psychology by architects or psychologists.

Elements above are also important to be understood by architects for supporting human performance. Human performance, as Steinfeld and Maisel (2012) explained, is the ability of people to complete activities and tasks.

For reaching the well functional architecture of Sekolah Luar Biasa (SLB/ Extraordinary Primary School), the government through the Ministry of National Education Directorate issued an Infrastructure Standard Regulation No.33/2008. Directorate of Extraordinary Education, Ministry of Education and Culture, also issued some guidelines related to Special Education including Technical Guidance for Extraordinary School Building through their official website (http://www.ditplb.or.id). Both of these documents are the guidance for architects/planners to achieve effectiveness and efficiency of education through producing design that is functional, reflecting the general and specialized characteristics of education, and low-cost maintenance.

In the case of accessibility standards for the blinds, that have to be covered by the school, two regulations above or the Regulation of the Minister of Public Works No.30/PRT/M/2006 have clearly shown the needed instruments, such as pedestrian paths, parking areas, doors, and etc. But, it doesn't present the possibility of architectural design exploration as well as its interaction with the users. Therefore, universal design has been developed to be more user-based design and at the same time, still provides room of creativity for designers/architects.

What this research did is recording and analyzing how users (blind students and teachers) actually understand the school's architecture. This study asked and formulated specific characters of visual impairment students in their process of reading architecture; and also identified architectural elements that help the learning process, the performing of effective and efficient activities, and also the positive experiences gained. The finding of this research is the manifestation of - as Steinfeld and Maisel (2012) said - four key bodies of knowledge that come into play on human performance; those are anthropometry (body fit), biomechanics (comfort), perception (awareness), and cognition (understanding).

\section{RESEARCH METHOD}

The study was conducted through four stages as follows:

1. Stage 1 - Preparation

At this stage, the activities that are done are:

a. The study of literature

Many studies of architecture components, accessibility issues, and physical characters of human psychology (particularly children learning age) conducted by researchers from various fields. The result of these studies is used as references or even provokes the birth of ideas in research.

b. Preparation of materials and research equipment. SLB (Extraordinary school) that is selected as the locus of this research is Islamic Junior High School (MTs) Yaketunis which is located in Jalan Parangtritis 46 Yogyakarta. The first task undertaken was re-measurement and depiction of existing conditions (floor plans, elevations and pieces of the buildings). Plan will be key questions in this study. 


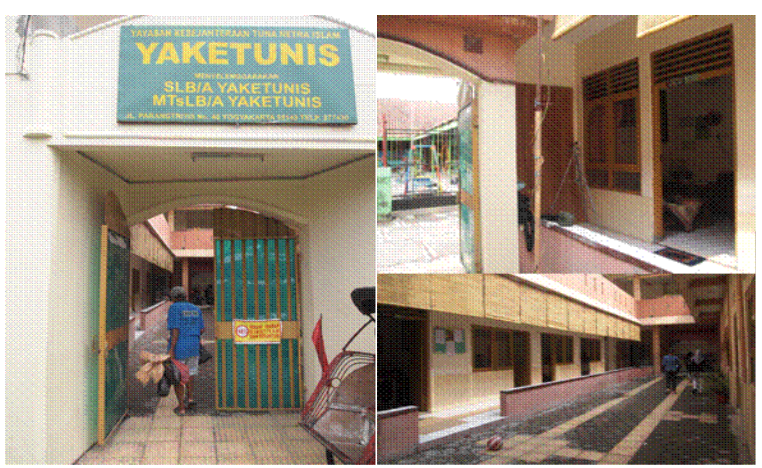

Figure 1. Atmosphere of Existing MTs Yaketunis

\section{Stage 2 - Field Survey}

a. Observation

In the observation phase, the activities were focused on students' behavior and their interaction with MTs Yaketunis architecture. The total 17 students can be categorized into two groups which are blind and low vision students (see table 1), and for this papers, the discussion will focus only on the blind one. But to add the number of objects, the observation was carried out on two blind teachers too. These observations took on number of students as the observed objects with the method of person-centered map (by using 2 camcorders, cameras, and direct observations) to record and to document any activities undertaken within a certain period.

Table 1. Number and Condition of MTs Yaketunis Students

\begin{tabular}{lc}
\hline \multicolumn{1}{c}{ CONDITION } & AMOUNT \\
\hline Blind & 7 \\
Low Vision & 10 \\
TOTAL & 17 \\
\hline
\end{tabular}

In the process of research, observation was focused on areas outside the corridor in front of the first floor where there are classrooms contacts with teacher's room, computer lab, library, toilets, dormitories, parking, and entrance hall. The selection is due to several reasons which are:

i. Most of activities around the school were performed in the first floor corridor

ii. More dynamic activities were done as far as this corridor.

In addition to the limitation of this observation, observation time was limited as well, that is only at break times are at 09:40 to 10:05 and 11:55 to 12:15 where most students and teachers activities were done outside the class.

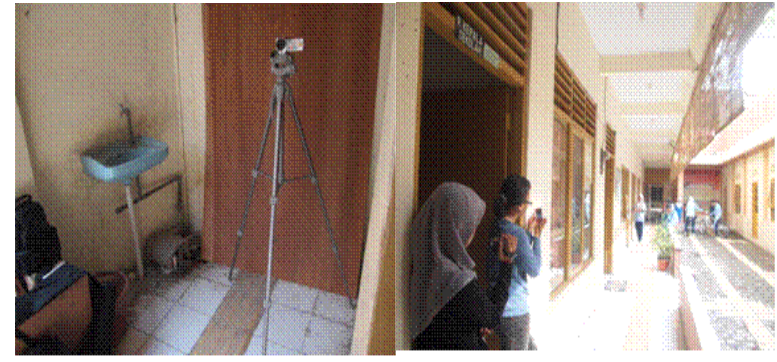

Figure 2. Observation Atmosphere

b. Interview

The interview process became the verification and also a deepening process for the observations result. This process is done to the students and teachers who became the object of observation.

3. Stage 3- Analysis of data

Analysis the results of the field survey will lead to three points, namely:

a. An analysis of the individual characters of blind student to study the visually impaired student attitudes toward their school.

b. An analysis of the architectural elements that are actively responded by the students SLB

c. An Analysis of the interaction of students and their SLB's architecture

\section{Stage 4 - Writing}

Writing stage was a systematic collecting process of the survey results and discussion (analysis) according to the research objectives.

\section{RESEARCH RESULTS AND DISCUSSION}

\section{Character of Blind Students}

Blind is part of different ability (diffable) community where blinds have different way to solve a problem. It can be defined as a group with significant limitation of visual capability that can be caused by illness, trauma, a derivative or degenerated condition that cannot be corrected by conventional means, including medical or surgical (Kurniawan, 2011). Limitations of this group can be understood through multiple conditions (Kurniawan, 2011) such as:

a. Difficulty on getting the details of the environment, when everything looks foggy.

b. Observing only large objects or simply recognizing shadow and light.

c. Recognizing glare from shiny floors and walls with high reflectivity, such as direct or bright light from windows.

d. Not being able to see in low light conditions. 


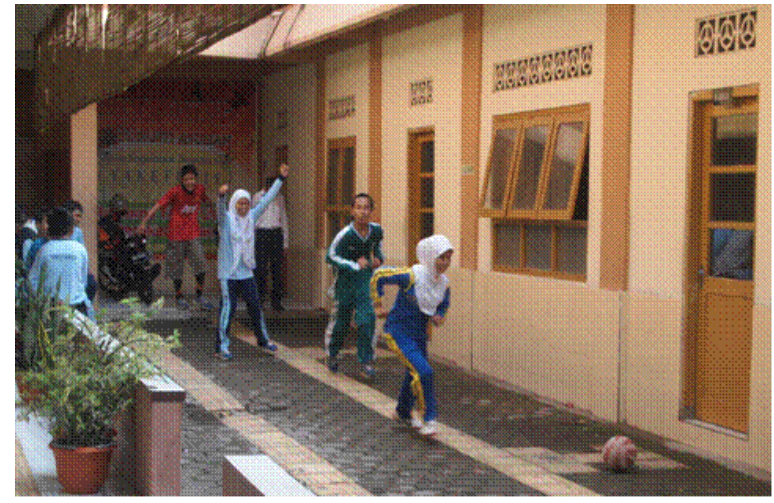

Figure 3. Sport Activities in Mts Yaketunis

But even when they share similar general limitations; each blind person has different level of abilities and characteristics. As the result of observation and interviews, all objects could not be generated into similar result. This diversity appears to be strongly influenced by the ability of each individual taken, for example Jamil, could be said, had a very unique ability. During observation, especially in the Saturday, November $10^{\text {th }}$ 2012, where sports activities performed, Jamil participated actively in the football game with other three students and two low vision students. In the record, It does not seem that Jamil (see figure 3, Jamil is a student dressed in a green sports/second person from the right) has limited movement because of his eyesight, even on the contrary, Jamil's move as active as students with low vision. Jamil is very sensitive to weather, wind, and sounds so he never hits even when he runs near it. Dita, as in an interview, still has the ability to see the light. This capability making her can still find out if there is an object in a place as a shadow, although she cannot clearly describe the object.

\section{Mobility}

a. Path of Movement

Observations indicated that the pattern of straight movement is done by almost all observed objects (see figure 6). The difference lies in the position of the movement occurred that there are movements in the middle of the corridor and also on the side of the corridor (near the wall, see figure 4). Another point that can be observed is that the movement pattern of visually impaired students is look much simpler than low vision students. The decision to move is based on a very predetermined goal, so that movement becomes very efficient and without the exploration of space. For example, blind students who walked toward the class from dormitory are walked straight along the corridor directly to the classroom. Interruptions that arise along the way (like a call from a friend in another class) responded with a pause (transit) corridors or sit on the bench just for a while.

b. Mobility Behavior

Some behaviors are found during the observations (see figure 5), those are:

1. Fingering the wall while walking or when looking for something or trying to find rooms/objects around them (figure 7).

2. Tending to walk in the near side of the wall.

3. Walking slowly, especially when passing through the class or group of friends.

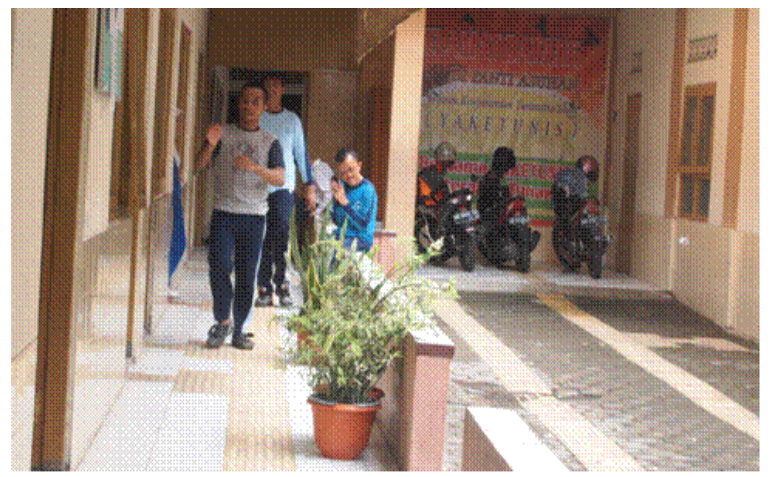

Figure 4. Patterns in the student movement corridors
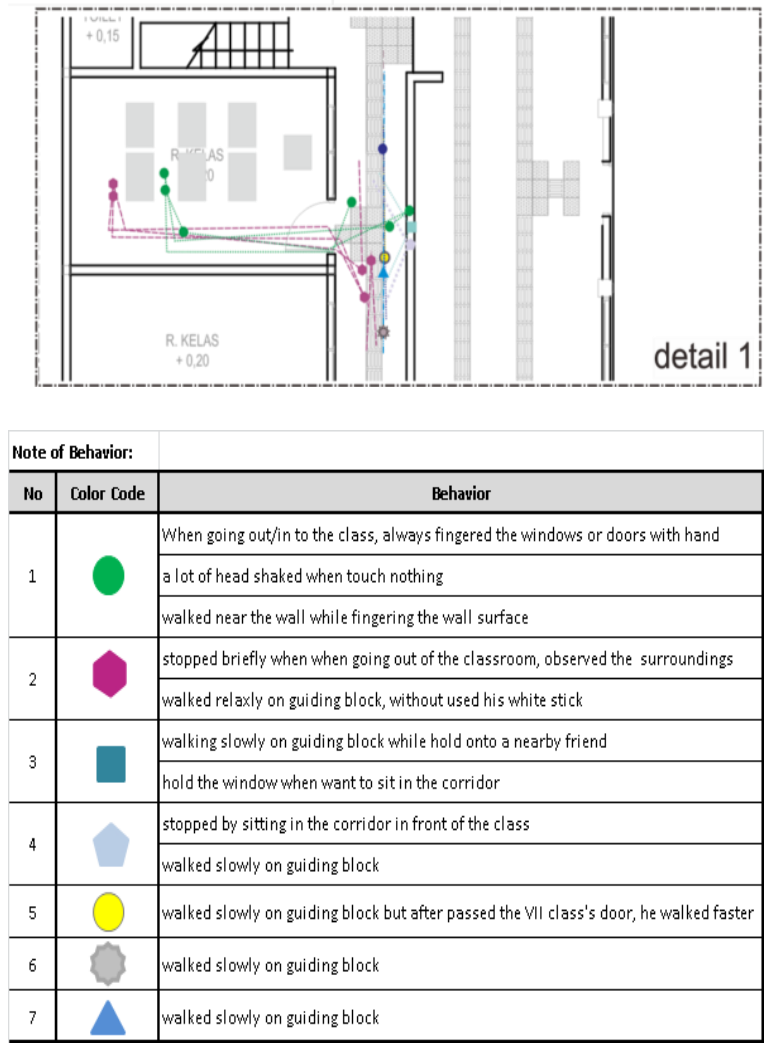

Figure 5. Behavior Held during the Mobility (at November $6^{\text {th }}, 2012$ Observation) 

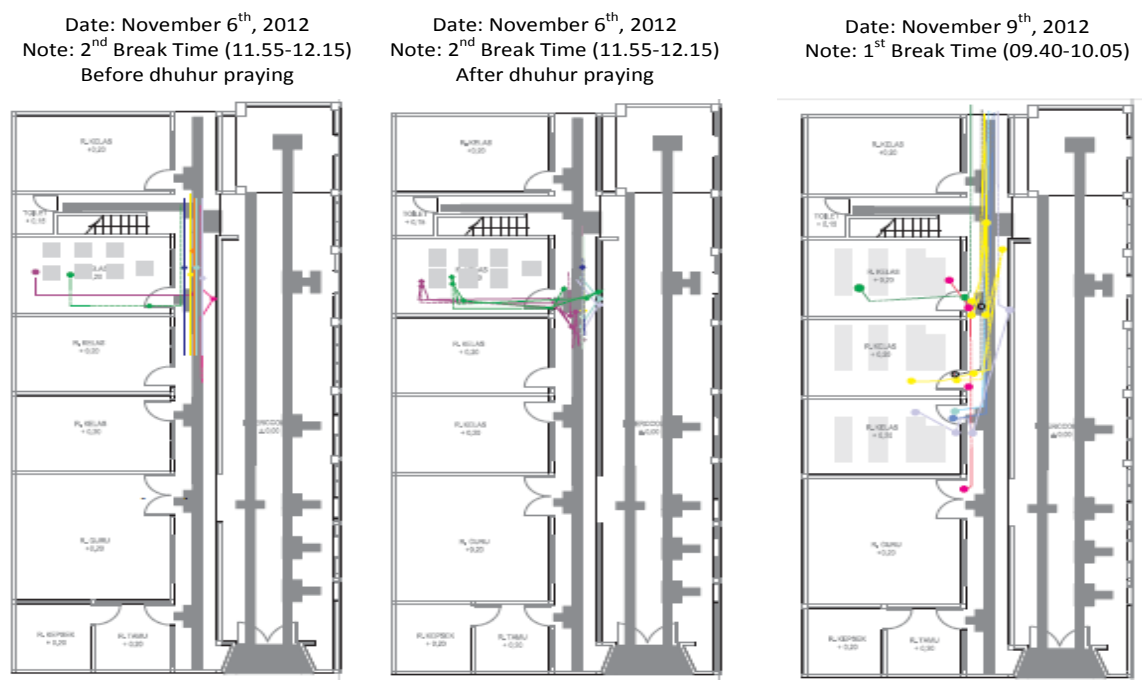

Date: November $10^{\text {th }}, 2012$ Note: $1^{\text {st }}$ Break Time $(09.40-10.05)$

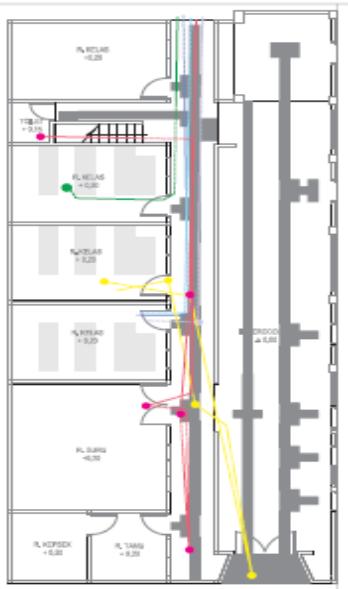

Figure 6. Movement Path on Several Observation Times

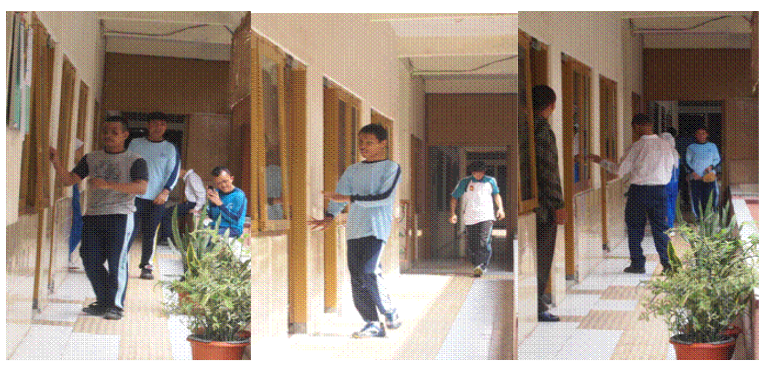

Figure 7. Few Visually Impaired Students Look Touched the Wall When the Mobility in This Corridor

Those characters show how collecting information is a different activity for the visually impaired person. Pasinni (1984) in his book 'Wayfinding in Architecture' explains the way blind people read their environment. He said that the blind, even though they have never seen, is capturing the environment in terms of cognitive maps. When the blind finds their way, he does not only replace visual information into non-visual information, but also he had to organize the information in an order fashion.

Thomson, Denny, and Deney, (1984) said that the main requirement for totally blind people is the non-visual clues such as the change in surface texture, embossed letters and appropriate acoustics, while people with limited vision (partially sighted) can depend on a lot more user-visual clues and can benefit from direct light or lighting designed, large font and color codes.

\section{Element of Architectures}

a. Room Layout

The MTs Yaketunis' room layout which is simple and arranged linearly allows blind students and teachers to memorize the order of room arrangement easily. Memorizing room arrangement has become a method for blind students and teachers here to find the room. Mrs. Atun (one of blind teacher), in an interview, for example, mentioned the room arrangement as follows:

"From the gate to the left, there is the head of school office, teachers' offices, IXB class, VIII class, VII class, stair, computer room, library, prayer room. In the east side there is a bathroom, a kitchen, girl's room, music room, hall, UKS room - but not yet arranged, and message, bathroom, garage in that corner. Above, there is the hall, recording studio, IXA class, language laboratory."

Mrs. Siti (blind teacher) described the layout as follows:

"Next to the teacher classroom there are classes. Right here is IXB class, VIII class, VII class, stair, computer laboratory. If we go upstairs, there is a IXA class."

Jamil (blind student) also described a similar arrangement of space:

"From the north, there is the mosque, then the library, laboratory, and then the stair to go upstairs for IXA class, next to the stair is VII class, VIII class, XIB class, office, and the guest room. In the East, there is bathroom, car garage; next extracurricular room but I do not know what is it for now, then the hall and the music room."

There are two things that become as note here:

1. Memory of rooms' arrangement is done as a series of rooms. It also indicates that blind person pictures the building on their cognitive map as a linear building. 
2. The movement pattern is affected by the way they arrange the rooms. Two teachers (Mrs. Atun and Mrs. Siti) who always come in from the gate will find the head school office and teacher room as their first room, and it is indicated in their explanation about the room arrangement. Meanwhile, Jamil who live in dormitory inside the school memorizes the mosque as the first room met from his dorm.

b. Wall

Walls, doors and windows become elements that most numerous interact with blind students and teachers in this school. In observation, researchers recorded a practice of touching or fingering the walls appeared repeatedly. The existence of walls and doors here are not to keep the students' balance while walking, but as a marker (sign) to recognize the rooms. For example, the walls will be the sign for the room so when the wall is stopped (where the stairs and the bathroom were) the students will identify it as the position of stairs and bathrooms and recognize the rooms before and after this wall-end area. The position of doors and windows as well as the door size mark the classroom or room identity.

c. Guiding block

During observation, guiding block was utilized by students and teachers on their movement. As recorded by the documentation of observation, students and teachers who walked in the middle of corridor were walk just on the guiding block. When the confirmation interview was done, all interviewees said that guiding block is useful in general but they do not used it for activity because of their good memories of the MTs buildings situation.

\section{CONCLUSIONS AND SUGGESTIONS}

Conclusions:

1. The proximity of the students/teachers with the school buildings has big influence on the patterns and behavior of movement.

2. Although it is useful in general, but adding auxiliary instruments such as guiding block do not become the main instrument for the movement.

3. The linear room arrangement is very helpful to memorize the position of a room to another room.
4. The implementation of architectural elements such as doors, windows, and walls can be used as a marker of the room.

5. The uniqueness of each individual ability also conducted different behavior detailed during movement.

6. Fingering behavior becomes major activity undertaken to determine the room marker, the objects around them, as well as help them to perform smooth movement.

Suggestions:

1. Research can be carried out with experimental or comparative method (by bringing students to a new location or change the existing condition MTs) to see the consistency of behavior and adaptations made.

2. Interview should be conducted more intense due to the proximity between researcher and student/ teacher is highly influential. The limitation of interviewing time also restrains further questions' exploration.

\section{REFERENCES}

Ching, D.K. (1996). Bentuk, Ruang, dan Susunannya. Jakarta: Penerbit Erlangga.

Exner, U. and Pressel, D. (2009). Basic Spatial Design. Birkhäuser, Basel

Kurniawan, H. (2011). Familiarity in Designing a Mosque: A Practice of Universal Design. Paper UIA World Congress 2011, Work Programme Architecture for All, Tokyo , Japan

Pasinni, R. (1984). Wayfinding in Architecture. John Wiley \& Sons, Inc.

Steinfeld, E. and Maisel, J.L. (2012). Universal Design: Creating Inclusive Environments. New Jersey: John Wiley \& Sons, Inc., Hoboken.

Thomson, N., Dendy, E. and de Deney, D (ed.). (1984). Sports and Recreation Provision for Disabled People. London: The Architecture Press Limited.

Unwin, S. (2003). Analysing Architecture (second edition). Routledge, Oxon.

--- . Peraturan Mentri Pekerjaan Umum (Permen PU) (Ministerial Regulation of Public Works) No. 30/PRT/M/2006 Tentang Pedoman Teknis Fasilitas dan Aksesibilitas dan Gedung dan Lingkungan. Jakarta. 